\title{
Everybody Present: Exploring the Use of an In-Class Meditation Intervention to Promote Positive Mental Health Among University Students
}

\author{
Paula Gardner and Kaitlyn Kerridge \\ Brock University
}

\begin{abstract}
There is a growing mental health crisis among university students in Canada. The purpose of this pilot study was to explore the effect of an in-class mindfulness intervention on the mental health of undergraduate students. Cross-sectional design was used and data were collected using self-reported questionnaires that included scale-rated and open-ended questions $(n=435)$. Integrating open-ended themes with statistical findings, the final analysis suggests the intervention had a positive effect on the mental health of student participants. A classroom environment that fosters learning, builds community, and encourages compassion were identified as ways in which the intervention "works" to promote positive mental health.
\end{abstract}

Keywords: mental health promotion, mindfulness-based intervention (MBI), university students, meditation

\section{RÉSUMÉ}

Au Canada, les problèmes de santé mentale s'aggravent singulièrement chez les étudiants de niveau universitaire. Le but de cette étude pilote était d'explorer les effets sur la santé mentale des étudiants de premier cycle d'une intervention en classe basée sur la pleine conscience. Un plan transversal a été utilisé, et les données ont été recueillies à l'aide de questionnaires autorapportés comprenant des questions à échelle graduée et ouvertes $(n=435)$. En fin de compte, l'analyse intégrant des thématiques libres aux résultats statistiques laisse entendre que l'intervention a eu un effet positif sur la santé mentale des étudiants ayant participé à l'étude. Un milieu scolaire qui favorise l'apprentissage, renforce l'esprit de communauté et encourage la compassion a été identifié comme étant un moyen d'intervention « efficace » pour promouvoir le bien-être mental.

Paula Gardner, Department of Health Sciences, Brock University, St.Catharines, Ontario; Kaitlyn Kerridge, Faculty of Applied Health Sciences, Brock University, St. Catharines, Ontario.

Correspondence concerning this article should be addressed to Paula Gardner, Department of Health Sciences, Brock University, 1812 Sir Isaac Brock Way, St. Catharines, ON L2S 3A1. Email: paula.gardner@brocku.ca 
Mots clés : promotion de la santé mentale, intervention basée sur la pleine conscience (IBPC), étudiants de niveau universitaire, méditation

Mental health problems are a growing public health concern. Findings from recent reports and crosssectional studies illustrate this concern including: one in five Canadians experience a mental health problem in any given year, mental illness is the leading cause of disability in Canada (CMHA, 2012), teenagers and young adults aged 15 to 24 experience the highest incidence of mental disorders of any age group (CMHA, 2013), and worldwide, suicide is the second leading cause of death among young people (WHO, 2017).

These trends are reflected on college and university campuses across Canada where a recent study revealed $57 \%$ of college and university students are feeling "overwhelming anxiety" and $38 \%$ report feeling "so depressed that it was difficult to function" (American College Health Association, 2016). Depression and anxiety have been found to negatively influence academic performance, increase the risk of dropping out of school, and lead to self-harming behaviours and even suicide (Hoban \& American College Health Association, 2007; Mackenzie et al., 2011).

As student mental health is increasingly prioritized on campuses across the country, academic administrators, student health services, and local health departments are expanding their efforts to identify and implement policies, programs, and resources to address the mental health needs of their students. Recent initiatives include the development of campus mental health websites, the addition of on-campus mental health communities of practice, and hiring more health professionals with specific expertise in mental health (e.g., mental health nurses). While campuses ramp up their efforts to support and treat students in crises, there is a simultaneous need for "upstream" preventative approaches that promote positive mental health among the campus community.

A mental health promotion strategy that is showing promise and receiving increased attention in both health and academia is mindfulness. Mindfulness is a practice of consciously bringing awareness to the present moment - to the here-and-now experience. Jon Kabat-Zinn, professor of medicine emeritus at the University of Massachusetts Medical School and a world authority on mindfulness, defines this practice as "paying attention in a particular way: on purpose, in the present moment, and non-judgmentally" (Kabat-Zinn, 2003). Reviews of the empirical literature on the effects of mindfulness on health conclude that mindfulness positively benefits both psychological health - including increased subjective well-being, reduced psychological symptoms and emotional reactivity, and improved behavioural regulation (Keng, Smoski, \& Robins, 2011) - and physical health, including reducing cortisol, blood pressure, heart rate, and other physiological markers of stress (Pascoe, Thompson, Jenkins, \& Ski, 2017).

Mindfulness and meditation practices are also emerging as effective ways to assist students to become more resilient in responding to the day-to-day pressures of campus life (Gardner \& Grose, 2015). Recent research suggests cultivating present moment awareness through mindfulness and meditation can improve academic performance by increasing attention, memory, problem solving skills, and concentration (Shapiro, Brown, \& Astin, 2008). Studies evaluating mindfulness-based stress management interventions are showing positive results including reduced student anxiety (Warnecke, Quinn, Ogden, Towle, \& Nelson, 2011) and 
reduction of depressive mood (Regehr, Glancy, \& Pitts, 2011). These practices have also been associated with students' ability to forge deeper connections with course material and an enhanced sense of compassion towards themselves and each other (Barbezat \& Pingree, 2012).

To date, research examining mindfulness-based interventions (MBIs) targeted at the university community is limited and the majority of studies focus on the impact of formal training programs. For example, Mindfulness Based Stress Reduction (MBSR) and Mindfulness Based Cognitive Therapy (MBCT) are delivered by counselling services or offered as extra-curricular workshops held outside of the university classroom. The purpose of this pilot study was to explore the effect of a mindfulness intervention program integrated directly into a course and delivered weekly to all students within their regular classroom environment.

\section{METHODS}

The study took place over a four-year period (2013-2017) and employed a cross-sectional survey design. All participants were third- and fourth-year undergraduate students in a health sciences program at a midsize Canadian university. The intervention, called "The Mindfulness Experiment" was led by the course instructor and consisted of a brief (2-3 minute) presentation on a particular aspect of mindfulness (i.e., what is it, how to do it, or the benefits of the practice), followed by a short (3-5 minute) group meditation that consisted primarily of instructions related to physically "settling" in the room and then using various breathing techniques to help students focus and maintain their awareness on the present moment. The intervention took place weekly over a 12-week semester, at the beginning of every lecture. The intervention was led by the same instructor and followed the same format in all courses. At the end of the semester, data were collected via anonymous self-reported questionnaires administered by the teaching assistant. The questionnaire included both scale-rated and open-ended questions aimed at understanding students' perceptions of the effect of the intervention on their mental health, including student learning and the classroom environment as key factors. A consent form was attached to the questionnaire and the study received approval from the university research ethics board.

Questionnaires were coded and inputted into SPSS (Statistical Package for Social Sciences) Version 20. In addition to frequencies and descriptive statistics, correlation matrices and multiple linear regression calculations were used to identify significant relationships and predictor variables.

Open-ended questions followed most of the scale-rated questions and were included to provide depth to findings and offer insights that may not be adequately captured in the closed-ended questions. The analysis of open-ended responses followed basic thematic analysis practices used in qualitative research: getting familiar with the data, generating initial codes, and searching, reviewing, and revising themes (Braun, Clarke, \& Terry, 2014). Details of this process for this particular study are provided below.

\section{Thematic Analysis of Open-Ended Questions:}

1. Getting familiar with the data: (transcription, reading/re-reading data)

- Responses to open-ended questions were inputted manually into a Word document by the research assistant (RA and second author on this paper), a trained qualitative researcher. During data 
entry, the RA kept analytic memos and pulled "important" quotes (i.e., those that "jumped out" as meaningful, interesting, informative, detailed, well-articulated, and/or different from others).

- All Word documents were read and re-read by the principal investigator (PI).

2. Coding: (systematically labelling common and interesting pieces of data across the entire data set)

- Independent of each other, the RA and PI performed initial coding of the data and each developed a list of codes (coding table).

- Coding tables were compared and discussed in several meetings between the RA and researcher and a final list was generated; there was full agreement between the two researchers at this stage.

3. Themes: (collating codes into themes, reviewing, collapsing, and refining themes to generate findings)

- Independent of each other, the PI and RA collated codes to generate themes.

- In analysis meetings, these individually generated themes were reviewed and refined, and a final list was agreed upon.

- For each theme, a summary narrative was created that included key quotes.

The final analysis was a process of integrating themes with the statistical results to generate overall findings. The RA and PI met on three separate occasions to compare and discuss the ways in which the preliminary findings from closed- and open-ended questions supported, explained, and contradicted each other. While actively searching for discrepancies and "tensions" between the statistical and thematic findings, the researchers could not identify any; there was strong agreement across findings. Final study results were generated by identifying and synthesizing the connections and symmetry between the two sets of findings to highlight meaning beyond simple description.

\section{RESULTS}

Data were collected from nine courses over the four-year period, and a total of 435 students completed the questionnaires (see Table 1, Study Participants). All nine courses were small (mean $=45$ students) upper year classes where participation (including in-class discussions and small group work) was recorded and counted towards student grades. As such, attendance was generally extremely high in these courses; on average, students missed a maximum of one class per 12-week semester. All students in all courses (except those who were absent for the final class when the evaluations were distributed) completed the evaluations and agreed to have their data used for the study. Most participants were female (79\%) and under the age of $24(88 \%)$, which is reflective of undergraduate health science programs in Canada. Half of the students surveyed had taken at least one other course with the professor and therefore had previous experience with the in-class meditation intervention.

\section{Self-Reported Effect on Students}

Student responses to The Mindfulness Experiment were overwhelmingly positive. Analysis suggests the practice helped to reduce feelings of anxiety and enhanced listening and attention among participating students (See Table 2, next page, Effect on the Students). 
Table 1

\section{Study Participants}

\begin{tabular}{lrr}
\hline Variables & Frequency & Percentage \\
\hline Age & 379 & \\
$\quad<24$ & 32 & 87.7 \\
$25-29$ & 21 & 7.4 \\
$>30$ & & 4.9 \\
& & \\
Sex & 89 & 20.6 \\
$\quad$ Male & 343 & 79.4 \\
Female & & \\
& & 49.0 \\
Previously taken a course with this professor* & 159 & 51.0 \\
$\quad$ Yes & 153 & \\
No & & \\
\hline
\end{tabular}

*Note: valid percentage used; 123 missing in this statistic as this question was not included in the first year of the study.

Almost all (93\%) participants agreed with the statement that the in-class meditation made them feel more calm and relaxed than when they arrived for class. The open-ended responses provided insight into how this "worked" as many students described how the practice initiated both physiological and psychological changes. For example:

Helps me control my breathing and heart rate, which calms me down. (Participant \#167)

Mindfulness really helps calm all thoughts of anxiety and depression and makes me slow down in the rat race of school. (Participant \#36)

In their open-ended responses students frequently described feeling overwhelmed and "stressed out" as they struggled to balance school, work, friends, and family life, and that it was often small daily frustrations - like computer problems or unexpected changes to work schedules - that tipped them into what they referred to as "unbalance." Students reported looking forward to the meditation as it acted as a kind of "reset" that then enabled them to cope with the rest of their day:

I looked forward to the meditation and always felt better afterwards. (Participant \#09)

It always put a more positive and relaxed outlook on my morning, regardless of how stressed out I was when starting. (Participant \#389)

In addition to helping students feel better able to manage their lives after class, the meditation also reportedly helped students be prepared for class. Most participants (83\%) thought the meditation helped 
Table 2

Effect on the Students

\begin{tabular}{|c|c|c|c|}
\hline Variables & Frequency & Percentage & Combined \\
\hline \multicolumn{4}{|c|}{ The in-class meditation made me feel more calm and relaxed than when I arrived to class. } \\
\hline Strongly Agree & 246 & 56.6 & \multirow{2}{*}{$93 \%$} \\
\hline Agree & 159 & 36.6 & \\
\hline Undecided & 21 & 4.8 & $5 \%$ \\
\hline Disagree & 8 & 1.8 & \multirow{2}{*}{$2 \%$} \\
\hline Strongly Disagree & 1 & 0.2 & \\
\hline \multicolumn{4}{|c|}{ The in-class meditation helped me focus on what was being taught in class. } \\
\hline Strongly Agree & 154 & 35.4 & \multirow{2}{*}{$83 \%$} \\
\hline Agree & 207 & 47.6 & \\
\hline Undecided & 58 & 13.3 & \multirow[t]{2}{*}{$13 \%$} \\
\hline Disagree & 15 & 3.4 & \\
\hline Strongly Disagree & 1 & 0.2 & $4 \%$ \\
\hline \multicolumn{4}{|c|}{$\begin{array}{l}\text { I was a better listener during the class (to the instructor and other students) because we started every class with a } \\
\text { meditation. }\end{array}$} \\
\hline Strongly Agree & 145 & 33.3 & \multirow{2}{*}{$75 \%$} \\
\hline Agree & 180 & 41.4 & \\
\hline Undecided & 85 & 19.5 & $19 \%$ \\
\hline Disagree & 24 & 5.5 & \multirow{2}{*}{$6 \%$} \\
\hline Strongly Disagree & 1 & 0.2 & \\
\hline
\end{tabular}

them focus more effectively on the material being presented, and $75 \%$ indicated they were better listeners (to the instructor and to other students) as a result of the meditation.

There were some students $(2-4 \%)$ who disagreed with positive statements about the effect of the meditation. In most of these cases the open-ended comments section was left blank. Students who did provide a comment reported to be unsure or unconvinced of the benefits of the practice or believed they didn't need it:

I think I'm already focused in class and so this doesn't make a difference. (Participant \#78)

I'm just not sure meditation helps me in any way. (Participant \#103)

In summary, the majority of participating students felt that the in-class meditation practice had a positive effect on their mental health and learning. Taking time at the beginning of each class to pause and pay attention to the present moment seemed to help students cope with daily frustrations and prepare them for a successful learning experience which, in turn, further supported their positive mental health. 


\section{Effect on the Classroom Environment}

Analysis suggests the in-class meditation also had a positive effect on the learning environment. Beginning each lecture with a group meditation created a classroom atmosphere that student participants perceived as calm and conducive to participation, and where students felt a sense of connection to each other and the instructor (see Table 3, next page, Effect on the Classroom Environment).

Almost all students (93\%) felt the classroom was changed - "much quieter and calmer"-as a result of the practice. In their open-ended responses, they explained this by describing how classrooms are often "noisy," "confusing" and even "chaotic" places, particularly in the first few minutes. While this class started out similarly, the meditation apparently served to transform the space. The calmer, quieter post-meditation classroom was welcomed by the majority of students and appeared to have a particularly positive effect on students who self-identified as being easily over-stimulated, having trouble "switching gears," or those who self-disclosed that they had been diagnosed with depression or anxiety:

My anxiety and depression really benefit from taking a few minutes out of the day to be mindful. (Participant \#245)

I think it was very helpful... benefited me and my anxiety, stress, ADHD, and even depression! (Participant \#401)

Statements such as these were included in open-ended responses by approximately 5-10\% of students.

In addition to a calmer space, most students (83\%) agreed with the statement that the practice fostered a "safe" learning environment where they felt comfortable participating in class discussions and activities. Their comfort and increased willingness to participate may also be a result of students (81\%) feeling that the group meditation fostered a sense of community in the classroom where they felt connected to their peers and their professor. A core theme that emerged from the open-ended responses was students' "sense of belonging." Participants linked these feelings to the collective practice of the meditation as a shared experience that drew them together:

Just closing my eyes for 3-4 minutes calmed me down during such a busy day. And I liked how the whole class did it together; it felt like it "equalized" everyone and gave everyone the same platform to start the class off from. (Participant \#115)

There were some students $(2-5 \%)$ who disagreed with positive statements related to the effects of the meditation on the classroom environment. Interestingly, the open-ended comments from these students suggest that they may have experienced some benefit despite indicating otherwise on the scale-rated questions:

I don't do the meditation and don't think it's really helpful. But I do find just sitting quietly for a few minutes with everyone before class begins is good for me. (Participant \#52)

This seeming contradiction may be caused by students feeling uncomfortable with the language associated with the intervention, i.e., "meditation" and "mindfulness."

In summary, the group meditation helped to cultivate a classroom environment that was calm and supportive, where students felt a sense of belonging, connection, and compassion towards their classmates and the instructor. Having a social environment that is supportive, compassionate, and where people feel 


\section{Table 3}

Effect on the Classroom Environment

\begin{tabular}{|c|c|c|c|}
\hline Variables & Frequency & Percentage & Combined \\
\hline \multicolumn{4}{|c|}{ The classroom felt much quieter and calmer after the meditation. } \\
\hline Strongly Agree & 231 & 53.3 & \multirow{2}{*}{$93 \%$} \\
\hline Agree & 172 & 39.7 & \\
\hline Undecided & 23 & 5.3 & \multirow{3}{*}{$\begin{array}{l}5 \% \\
2 \%\end{array}$} \\
\hline Disagree & 7 & 1.6 & \\
\hline Strongly Disagree & 0 & 0 & \\
\hline \multicolumn{4}{|c|}{$\begin{array}{l}\text { The meditation helped to create a classroom community where students felt connected to their peers and the } \\
\text { professor. }\end{array}$} \\
\hline Strongly Agree & 127 & 40.7 & \multirow{2}{*}{$81 \%$} \\
\hline Agree & 127 & 40.7 & \\
\hline Undecided & 42 & 13.5 & \multirow{3}{*}{$\begin{array}{r}14 \% \\
5 \%\end{array}$} \\
\hline Disagree & 15 & 4.8 & \\
\hline Strongly Disagree & 1 & 0.3 & \\
\hline \multicolumn{4}{|c|}{$\begin{array}{l}\text { I think the meditation helped to create a 'safe' learning environment and a place that I felt comfortable and willing } \\
\text { to participate in class discussions and activities. }\end{array}$} \\
\hline Strongly Agree & 122 & 39.1 & \multirow{2}{*}{$83 \%$} \\
\hline Agree & 137 & 43.9 & \\
\hline Undecided & 39 & 12.5 & $13 \%$ \\
\hline Disagree & 13 & 4.2 & \multirow{2}{*}{$4 \%$} \\
\hline Strongly Disagree & 1 & 0.3 & \\
\hline
\end{tabular}

connected to one another is a strong determinant of positive mental health (Wilkinson \& Marmot, 2003; World Health Organization, 2014).

\section{A Cumulative Effect}

The comparative analysis revealed that prior experience predicted students feeling positive about the meditation practice. Statistically significant relationships were found between "having taken a course previously with the professor" and almost all outcome variables, including "better listener," "more focused," "feeling a quieter calmer classroom," "a safe learning environment," "connection to peers and instructor," and "feeling less anxious about life generally." These results suggest a potential cumulative effect of the intervention and highlight a central principle of meditation - that it is a "practice." While simple to conceptualize, the practice of meditation is challenging and, much like other skills, require a great deal of practice. 


\section{DISCUSSION}

The purpose of this exploratory study was to better understand the effect of The Mindfulness Experiment on the mental health of student participants. As a pilot study seeking new insights and a more complex understanding of how students conceptualize their experience, emphasis was placed on findings that integrated open-ended responses with results from scale-rated questions. Results from this study suggest that a brief MBI delivered directly into an undergraduate classroom can be a positive experience for participants. Students participating in The Mindfulness Experiment agree with statements about the benefits of the practice and go on to describe how it enhances their ability to listen, focus, and learn; how it provides a calm pause in what is usually a stressful, chaotic day; and that practicing in a group fosters a sense of community within the classroom.

Listening is different from hearing in that it is selective and purposeful; the ability to fully concentrate on what is being said rather than passively "hearing" the message of the speaker is an important learning skill. Cultivating attention (i.e., focus and active listening) is a core attribute of mindfulness and meditation practices (Center for Contemplative Mind in Society, 2017; Greater Good Science Center at UC Berkeley, 2017) and previous research demonstrates a positive relationship between these contemplative practices and attention (Good et al., 2015; Mrazek, Franklin, Phillips, Baird, \& Schooler, 2013). In an era of constant distractions where multi-tasking is routine, the ability to focus deeply and really pay attention in a particular moment has also been described as essential to productivity (Goleman, 2013).

The ways in which The Mindfulness Experiment seems to act as a protective factor against daily stressors for students mimics previous research. Findings from a recent systematic review and meta-analysis of the literature on mindfulness and stress for example, demonstrated that meditation practice can lead to decreased physiological markers of stress, including reduced cortisol, heart rate, and blood pressure in a range of populations (Pascoe, Thompson, Jenkins, \& Ski, 2017). That The Mindfulness Experiment seemed to resonate strongly with students with existing mental health problems is supported in the literature. There is increasing evidence to demonstrate the benefits of MBIs for people diagnosed with a wide range of mental health problems including anxiety, depression, and PTSD (Gotink et al., 2015; Kuyken et al., 2016; Stephenson, Simpson, Martinez, \& Kearney, 2017). Findings from this study joins others to suggest mindfulness and meditation practices have an important place alongside traditional cognitive and pharmacological therapies.

Finally, connection to others is a foundational element of contemplative practices (Duerr, 2015). Previous research demonstrates mindfulness and meditation support interpersonal relationships and community building by enhancing communication and empathy towards others (Barnes, Brown, Krusemark, Campbell, \& Rogge, 2007; Dekeyser, Raes, Leijssen, Leysen, \& Dewulf, 2008; Lim, Condon, \& DeSteno, 2015; McGill, AdlerBaeder, \& Rodriguez, 2016).

How "sitting in stillness" generates such benefits as those reported by these students is the focus of a rapidly growing body of neuroscience research. Recent brain imaging studies reveal meditation can literally change our brains - building grey matter in regions dedicated to memory and attention and shrinking parts of the brain (the amygdala) where our "fight or flight" responses reside (Lazar, 2005; Treadway \& Lazar, 2010).

The Mindfulness Experiment is positioned as a health promotion tool that is inclusive of all students rather than targeting specific "at risk" groups such as those previously diagnosed with mental disorders or 
those enrolled in studies deemed particularly challenging and where students are reporting high levels of stress and anxiety (e.g., medical training programs). To date, the majority of MBIs reported in the literature either target a certain population of students or are delivered outside the classroom setting. For example, Galante and colleagues evaluated the provision of an 8 -week mindfulness intervention course delivered to university students $(\mathrm{n}=616)$ in the UK as 90-minute workshops delivered outside of regular class time (Galante et al., 2018). Results from their randomized controlled trial showed improved well-being during exam periods and after the course for students who received the MSS (Mindfulness Skills for Students) training in addition to mental health support as usual compared to students who only received the mental health support as usual.

Recently there has been some research to assess in-class, brief meditation interventions similar to the current study. For example, in a qualitative exploratory study, researchers at an urban Canadian university examined the impact of a brief instructor-guided mindfulness practice on fifty-two graduate and undergraduate students from different disciplines. Results mirrored findings from the current study, as students reported the meditation helped them feel more focused and calm as well as more engaged with course content (Schwind, McCay, Beanlands, Martin, Martin, \& Binder, 2017). Similarly, the feasibility of The Mindfulness Experiment is high in terms of implementation. The brief, instructor-led intervention is integrated directly into the classroom setting, is less formal than MBSR and MBCT and therefore requires no special equipment, takes only a few minutes of class time, and requires very little training.

There are several limitations of this research, the most significant of which is the positivity bias associated with the questionnaire; most questions asked students to respond to positive statements related to the meditation practice (e.g., "The in-class meditation helped me focus on what was being taught in class"). In future research questionnaire design should address this limitation by rephrasing questions, and/or providing choices in answers that include negative consequences of the intervention, and also by administering the questionnaire at different times over the semester. Secondly, as an exploratory pilot study, it was not randomized and did not include a control group; as such, findings cannot be generalized to wider populations. Future research could include a control condition; for example, beginning every lecture with a few minutes of complete silence rather than any meditation instructions. Additionally, as all participants were health science students, there is the chance they may be predisposed to the need for, and benefit of, healthrelated interventions. Future research should include students from other disciplines. Finally, the professor leading the intervention was the same for all courses and as such there may be an instructor-effect; meaning findings are a result of the professor (personality, skill as an educator) as much as/rather than the intervention. Future research should include other faculty members. Other possible avenues for future research include delivering the intervention via audio or video and expanding the study to include examining the impact of the intervention on the instructor.

\section{CONCLUSION}

There is a transcendent feeling in being subsumed and surrendering to a group. One becomes a part of something larger than oneself, and something in our makeup rewards us when that happens. We cling to our individuality, but we experience true ecstasy when we give it up (Scottish-American singer, songwriter, and musician David Byrne, 2018). 
Concern for student mental health has become a campus priority as recent reports suggest a growing number of post-secondary students experience high levels of stress and anxiety and for many, mental disorders are common, lead to attrition, and typically go untreated (Auerbach et al., 2016). The World Health Organization predicts that by 2020 mental health issues will be the leading cause of disability at universities and colleges across the globe (WHO, 2013). The high rates of stress, anxiety, depression and other diagnosable mental illnesses among post-secondary students have been linked to school-related pressures, as many struggle to manage academic life with other responsibilities related to friends, family, and work (Ribeiro et al., 2017). Escalating levels of stress and anxiety among the student population, combined with evidence to show its association with poor academic performance (ACHA, 2007; Mackenzie et al., 2011), make university campuses an important site for mental health interventions.

Despite growing evidence to demonstrate why we should be integrating mindfulness practices into higher education - including boosting resilience, improving mood and buffering the association between academic stress and depression (Cole et al., 2015; McGillivray \& Pidgeon, 2015) - there is much less that describes how to do this. Particularly scant is research to explore MBIs that are inclusive of all students regardless of their mental health status, and those that are integrated directly into weekly lectures. Results from this pilot study suggest integrating meditation directly into post-secondary classrooms is a promising health promotion tool for building positive mental health among students. The authors of this study join others in a call to

those working across sectors to secure the will, knowledge, and resources necessary to build contemplative campuses across Canada as a progressive health promotion approach to the current mental health crisis.

\section{REFERENCES}

American College Health Association (ACHA). (2016). ACHA-NCHA II (American College Health Assessment-National College Health Assessment) Ontario Canada Reference Group Executive Summary Spring 2016. Retrieved from oucha.ca/pdf/2013_Reference_Group_Exec_Summary.pdf

American College Health Association (ACHA). 2007. American College Health Association National College Health Assessment Spring 2006 Reference Group data report (abridged). Journal of American College Health. 55(4):195-206.

Auerbach, R.P., Alonso, J., Axinn, W.G., Cuijpers, P., Ebert, D.D., Green, J.G., ...Bruffaerts, R.(2016). Mental disorders among college students in the World Health Organization World Mental Health Surveys. Psychological Medicine 46(14): 2955-2970.

Barbezat, D., \& Pingree, A. (2012). Contemplative pedagogy: The special role of teaching and learning centers. In James E. Groccia and Laura Cruz (Eds.), To Improve the Academy, p. 31, 177-191. San Francisco, CA: Jossey-Bass.

Barnes, S., Brown, K. W., Krusemark, E., Campbell, W. K., \& Rogge, R. D. (2007). The role of mindfulness in romantic relationship satisfaction and responses to relationship stress. Journal of Marital and Family Therapy, 33(4), 482-500.

Braun, V., Clarke, V., \& Terry, G. (2014). Thematic analysis. In P. Rohleder, A. Lyons, (Eds), Qualitative research in clinical and health psychology (pp. 95-113). Basingstoke: Palgrave MacMillan.

Byrne, D. (2018). Lead singer and guitarist of the Talking Heads reflecting on his experience singing with Choir, Choir, Choir in his online journal. Retrieved from http://davidbyrne.com/journal/how-do-they-do-it-part-2

Mental Health Commission of Canada. (2014). Why investing in mental health will contribute to Canada's economic prosperity and to the sustainability of our health care system. Retrieved from http://www.mentalhealthcommission.ca/English/node/742.

Canadian Mental Health Assocation. (2013). Fast facts about mental illness. Retrieved from http://www.cmha.ca/media/ fast-facts-about-mental-illness/\#.WVGA94qQwk8

Center for Contemplative Mind in Society. (2017). Retrieved from http://www.contemplativemind.org/ 
Centre for Addiction and Mental Health. (2012). About mental health and mental health problems. Retrieved from http:// www.camh.ca/en/hospital/visiting_camh/rights_and_policies/Pages/challenges_choices_aboutmhprob. aspx

Cole, N. N., et al. (2015). Predictor and moderator effects of ego resilience and mindfulness on the relationship between academic stress and psychological well-being in a sample of Ghanaian college students. Journal of Black Psychology 41(4), 340-357.

Dekeyser, M., Raes, F., Leijssen, M., Leysen, S., \& Dewulf, D. (2008). Mindfulness skills and interpersonal behaviour. Personality and Individual Differences, 44(5), 1235-1245.

Duerr, M. (2015). Tree of contemplative practices. The Center for Contemplative Mind in Society. Retrieved from http://www.contemplativemind.org/practices/tree

Galante, J., Dufour, G., Vainre, M., Wagner, A. P., Stochl, J., Benton, A., . . Jones, P. B. (2018). A mindfulness-based intervention to increase resilience to stress in university students (the Mindful Student Study): A pragmatic randomised controlled trial. The Lancet Public Health, 3(2), e72-e81.

Gardner, P., \& Grose, J. (2015). Mindfulness in the academy-Transforming our work and ourselves 'one moment at a time'. Collected Essays on Learning and Teaching, 8, 35-46.

Goleman, D. (2013). Focus: The hidden driver of excellence. New York, NY: Harper.

Good, D. J., Lyddy, C. J., Glomb, T. M., Bono, J. E., Brown, K. W., Duffy, M. K., . . Lazar, S. W. (2015). Contemplating mindfulness at work: An integrative review. Journal of Management, 42, 114-142. doi:0149206315617003

Gotink, R. A., et al. (2015). Standardised mindfulness-based interventions in healthcare: An overview of systematic reviews and meta-analyses of RCTs. PloS one 10(4): e0124344.

Greater Good Science Centre at UC Berkeley. (2017). What is mindfulness. Retrieved from http://greatergood. berkeley.edu/topic/mindfulness/definition

Hoban, M. \& American College Health Association. (2007). American college health association national college health assessment spring 2006 reference group data report (abridged). Journal of American College Health, 55(4), 195-206. http://dx.doi.org/10.3200/JACH.55.4.195-206

Keng, S.-L., et al. (2011). Effects of mindfulness on psychological health: A review of empirical studies. Clinical Psychology Review 31(6), 1041-1056.

Kabat-Zinn, J. (2003). Mindfulness-based interventions in context: Past, present, and future. Clinical Psychology: Science and Practice, 10(2), 144-156.

Kuyken, W., et al. (2016). Efficacy of mindfulness-based cognitive therapy in prevention of depressive relapse: An individual patient data meta-analysis from randomized trials. JAMA Psychiatry 73(6), 565-574.

Lazar, S. W. (2005). Mindfulness research. In R. D. Siegel, P. R. Fulton, (Eds.), Mindfulness and psychotherapy (pp. 220-238). New York, NY, US: Guilford Press.

Lim, D., Condon, P., \& DeSteno, D. (2015). Mindfulness and compassion: An examination of mechanism and scalability. PloS one, 10(2). doi:0118221

Mackenzie, S., Wiegel, J. R., Mundt, M., Brown, D., Saewyc, E., Heiligenstein, E., . . Fleming, M. (2011). Depression and suicide ideation among students accessing campus health care. American Journal of Orthopsychiatry, 81(1), $101-107$.

McGill, J., Adler-Baeder, F., \& Rodriguez, P. (2016). Mindfully in love: A meta-analysis of the association between mindfulness and relationship satisfaction. Journal of Human Sciences and Extension, 4(1), 89-111.

McGillivray, C. J., \& Pidgeon, A. M. (2015). Resilience attributes among university students: A comparative study of psychological distress, sleep disturbances and mindfulness. European Scientific Journal 11(5), 33.

Mrazek, M. D., Franklin, M. S., Phillips, D. T., Baird, B., \& Schooler, J. W. (2013). Mindfulness training improves working memory capacity and GRE performance while reducing mind wandering. Psychological Science, 24(5), 776-781. doi:0956797612459659

Pascoe, M. C., et al. (2017). Mindfulness mediates the physiological markers of stress: Systematic review and metaanalysis. Journal of Psychiatric Research 95, 156-178.

Regehr, C., Glancy, D., \& Pitts, A. (2011). Interventions to reduce stress in university students: A review and metaanalysis. Journal of Affective Disorders, 148(1), 1-11.

Ribeiro, Í. J., et al. (2017). Stress and quality of life among university students: A systematic literature review. Health Professions Education. https://doi.org/10.1016/j.hpe.2017.03.002 
Schwind, J. K., et al. (2017). Mindfulness practice as a teaching-learning strategy in higher education: A qualitative exploratory pilot study. Nurse Education Today 50, 92-96.

Shapiro, S. L., Brown, K. W., \& Astin, J. A. (2008). Toward the integration of meditation into higher education: A review of research. The Center for Contemplative Mind in Society. Retrieved from http://www/.contemplative mind. org/admin/wp-content/uploads/2012/09/MedandHigherEd

Stephenson, K. R., et al. (2017). Changes in mindfulness and posttraumatic stress disorder symptoms among veterans enrolled in mindfulness-based stress reduction. Journal of Clinical Psychology 73(3), 201-217.

Treadway, M. T., \& Lazar, S. W. (2010). Meditation and neuroplasticity: Using mindfulness to change the brain. In R. A. Baer (Ed.), Assessing mindfulness and acceptance processes in clients: Illuminating the theory and practice of change (pp. 186-205). Oakland CA: Context Press/New Harbinger Publications.

Warnecke, E., Quinn, S., Ogden, K., Towle, N., \& Nelson, M. R. (2011). A randomised controlled trial of the effects of mindfulness practice on medical student stress level. Medical Education, 45, 381-388.

Wilkinson, R. G., \& Marmot, M. (2003). Social determinants of health: The solid facts. World Health Organization.

World Health Organization. (2013). Mental health action plan 2013-2020. 2013. Retrieved from http://www.who.int/ mental health/action plan 2013/en/

World Health Organization. (2014). Social determinants of mental health: World Health Organization.

World Health Organization. (2017). Suicide fact sheet. Retrieved from http://www.who.int/mediacentre/factsheets/ fs $398 / \mathrm{en} /$ 